\title{
Nine-Phase Armature Windings Design, Test and Harmonic Analysis
}

\author{
H.E. Jordan, R.C. Zowarka, Jr, and S.B. Pratap \\ Center for Electromechanics \\ The University of Texas at Austin \\ Austin, Texas USA
}

\begin{abstract}
A nine-phase armature winding was developed for a large generator. Alternative methods for interconnecting the pole-phase groups were examined. An alternate-pole connection scheme was adopted and a prototype induction motor was constructed to confirm the winding scheme.
\end{abstract}

Since only a three-phase power source was available for testing, the induction motor was tested by using three, three-phase winding sections, one at a time.

Air-gap harmonic fields produced some unusual results. These test results and harmonic analyses to explain them are presented herein.

The tests confirmed the nine-phase winding scheme that was adopted. The harmonic analyses revealed that the complete ninephase winding exhibited a very low harmonic content, a distinct advantage of a nine-phase winding for future applications.

Keywords-induction motor, nine-phase, harmonic analysis

\section{INTRODUCTION}

Most electrical machines above a few kilowatts in rating are three-phase machines. The reasons for this are that three-phase power is the common electrical distribution system choice and three-phase machines can generally be designed for higher power density and lower cost than a single-phase machine of the same rating.

The University of Texas at Austin Center for Electromechanics is engaged in an application requiring a ninephase power system at power levels in excess of 1,000 kW. Consequently, a nine-phase generator had to be designed. The technical details of the application requiring the nine-phase power are not available for publication at this time. However, the details of the nine-phase armature winding and its characteristics are presented herein.

It is not surprising that the literature on electric machines with greater than three phases is rather sparse, given the predominance of three-phase power systems. Klingshirn [1,2] discussed what he termed as "high-phase order" motors, which includes many different phase combinations up to 18 phases. Nelson and Krause [3] presented an analog simulation of two types of six-phase motors. Coates, et al [4] discuss the performance of a nine-phase synchronous reluctance drive

This work was sponsored by the Department of the Navy through General Atomics under contract \#\#N68335-00-C-0189. although they do not provide any details of the nine-phase machine.

More recently, the increased use of inverter-motor drive systems to replace fixed frequency, 50 or $60 \mathrm{~Hz}$, motor installations has focused increased attention on "high-phase order" motors. For inverter-motor drives, only the inverter input is constrained to three-phases and the output can be designed for whatever number of phases optimizes the system. Williamson and Smith [5] have presented the merits of utilizing high-phase order machines. Benatmane, et al [6] have described a fifteen-phase, 19 MW induction machine developed for ship propulsion.

\section{NINE-PHASE WINDING}

There are at least two methods for creating a nine-phase winding. One choice is to wind each pole group with three, three-phase groups and then split each of the three-phase groups in a single pole into three individual phases. Of course, this requires selecting an appropriate number of slots so that the winding can be divided into nine equal sections assuming that an integral slot winding is desired.

The second choice, and the one used here, is to space the phase groups by 40 electrical degrees so that a nine-phase distribution exists in the air-gap mmf field. This requires reversing the polarity of each adjacent phase group similar to the commonly used $+\mathrm{A}$, $-\mathrm{B}$, $+\mathrm{C}$ phase arrangement for threephase, 60 electrical degree phase belt, three-phase windings. The resultant mmf waveform will be established by nine, equally spaced phase contributions. A phasor diagram displaying a comparison of the two winding arrangements is presented in Figure 1.

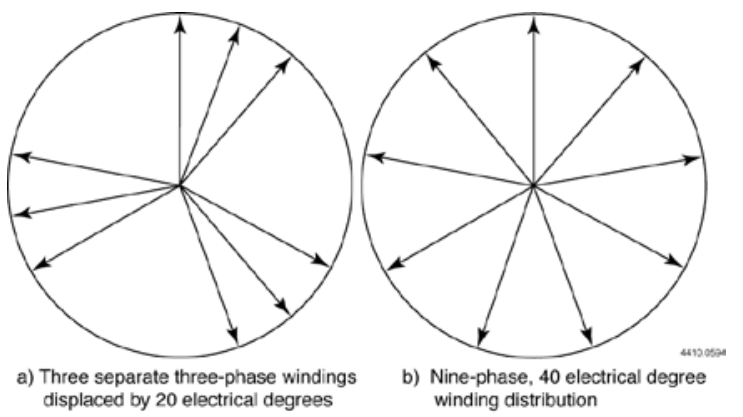

Figure 1. Phasor diagram for two different connections of a nine-phase winding 
Another choice to be made in the design of a nine-phase winding is the scheme to be used for the pole-to-pole connections. Connections of adjacent poles, called a "shortthrow" connection by Veinott [7], and connections that skip a pole, "long throw", are both used in three-phase windings. The alternate pole or "long-throw" connection was chosen for this design. One advantage of this connection was that it provided a more symmetrical magnetic force distribution on the rotor in the event of a fault at the load. Also, one would choose the connection scheme that was most easily implemented recognizing that there are three times more connections to be made in a nine-phase machine than in a three-phase machine. A suitable scheme of ring buses was developed which made the connection process feasible to implement.

\section{PROTOTYPE NinE-PhASE INDUCTION MOTOR}

The nine-phase connection scheme was checked with a finite element program and found to provide the desired field distribution. However, it was deemed desirable to verify that the design could be implemented and produce the desired rotating magnetic field essential to meeting the generator's performance goals. Therefore, a prototype nine-phase induction motor was constructed by rewinding an old Westinghouse 300 hp, 6 pole, $60 \mathrm{~Hz}, 460 \mathrm{~V}$ motor in a 686 frame. The motor was selected because it had 144 stator slots, which matched the number of slots to be used in the generator. A new eight pole, nine-phase induction motor design was developed. The Westinghouse motor was stripped and rewound to the new design. The winding was divided into six, three-phase groups and leads for each of these groups were brought out so that they were available for external connections.

\section{TEST}

Since only three-phase power was available, the motor could not be tested as a nine-phase machine. Instead, it was tested by connecting the three-phase power to various combinations of three-phase windings. The results of this test are presented in Table I.

TABLE I. RESULTS OF TEST \#1

\begin{tabular}{|l|c|l|}
\hline \multicolumn{1}{|c|}{ Connection } & $\begin{array}{c}\text { Maximum Speed } \\
\text { (rpm) }\end{array}$ & $\begin{array}{c}\text { Direction of } \\
\text { Rotation }\end{array}$ \\
\hline $\begin{array}{l}\text { Any one of the } 3 \text { phase } \\
\text { groups excited }\end{array}$ & 175 & Counter clockwise \\
\hline $\begin{array}{l}\text { Any pair of north-south } \\
3 \text { phase groups excited }\end{array}$ & 135 & Clockwise \\
\hline
\end{tabular}

These results were both surprising and puzzling. An eight pole induction motor operating from a $60 \mathrm{~Hz}$. source should operate at approximately $900 \mathrm{rpm}$ under no-load conditions. However, it is well known that space harmonics in the air gap magnetic field can cause the rotor to "hang-up" during acceleration at subsynchronous speeds. The fact that only a portion, i.e. three phases out of the nine phases, are excited at any one time guarantees that the air gap field will be rich in harmonics. In particular, the fifth space harmonic will rotate backward at approximately $180 \mathrm{rpm}$ and the seventh will rotate forward at approximately $128.5 \mathrm{rpm}$. These numbers match reasonably well with the speeds reported in the above table. The conclusion was that we were experiencing subsynchronous "crawling". The decision was made to conduct a second series of tests in which an external small motor would be used to drive the rotor to a speed above these subsynchronous "crawling" speeds and then apply three-phase power to determine if the motor would accelerate to $900 \mathrm{rpm}$.

The second test was performed by belt driving the ninephase motor with a small dc motor to accelerate the motor up to approximately $250 \mathrm{rpm}$ and then the three-phase power was applied to each north-south, three-phase group of windings separately. In every test, the motor accelerated to approximately $900 \mathrm{rpm}$ and the current dropped to a normal no-load value for the design, 20 to $30 \mathrm{~A}$. This confirmed the hypothesis that the asynchronous "crawling" which was experienced during the first test was, in fact, due to space harmonics. More importantly, this test also confirmed the correctness of the connection scheme by establishing that any three-phase group selected from the nine-phase winding operated as an individual three-phase motor.

In the interim, between the preparation of this paper and its presentation, the nine-phase generator was constructed and tested. It delivered the nine-phase output that was required.

\section{HARMONIC ANALYSIS}

As a consequence of the first attempt to accelerate the motor, a series of harmonic analyses were conducted to understand the behavior noted in Table I. The harmonic analysis technique is explained in Appendix A and the results of the analyses are summarized in Tables II, III,and IV.

TABLE II. SPACE HARMONICS GENERATED BY THE NINE-PHASE MOTOR

\begin{tabular}{|c|c|c|c|}
\hline $\begin{array}{c}\text { Order of } \\
\text { harmonic }\end{array}$ & $\begin{array}{c}\text { Number of } \\
\text { poles }\end{array}$ & $\begin{array}{c}\text { Per-unit value } \\
\text { CCW rotation }\end{array}$ & $\begin{array}{c}\text { Per-unit value } \\
\text { CW rotation }\end{array}$ \\
\hline 1 & 8 & 0 & 1.0 \\
\hline 2 through 7 & 16 through 56 & 0 & 0 \\
\hline 17 & 136 & 0.0052 & 0 \\
\hline 19 & 152 & 0 & 0.0046 \\
\hline 35 & 280 & 0.029 & 0 \\
\hline 37 & 296 & 0 & 0.027 \\
\hline
\end{tabular}

TABLE III. SPACE HARMONICS FOR A NINE-PHASE WINDING WITH ONE THREE-PHASE SET OF NORTH POLES ONLY EXCITED

\begin{tabular}{|c|c|c|c|}
\hline $\begin{array}{c}\text { Order of } \\
\text { harmonic }\end{array}$ & $\begin{array}{c}\text { Number } \\
\text { of poles }\end{array}$ & $\begin{array}{c}\text { Per-unit value } \\
\text { CCW rotation }\end{array}$ & $\begin{array}{c}\text { Per-unit value } \\
\text { CW rotation }\end{array}$ \\
\hline 1 & 8 & 0 & 1.0 \\
\hline 2 & 16 & 0.057 & 0.114 \\
\hline 4 & 32 & 0.103 & 0.051 \\
\hline 5 & 40 & 0.1188 & 0 \\
\hline 6 & 48 & 0.085 & 0.085 \\
\hline 7 & 56 & 0 & 0.041 \\
\hline 35 & 280 & 0.029 & 0.027 \\
\hline 37 & 296 & 0 & \\
\hline
\end{tabular}


TABLE IV. SPACE HARMONICS FOR A NINE-PHASE WINDING WITH ONE THREE-PHASE SET OF NORTH-SOUTH POLES EXCITED

\begin{tabular}{|c|c|c|c|}
\hline $\begin{array}{c}\text { Order of } \\
\text { harmonic }\end{array}$ & $\begin{array}{c}\text { Number } \\
\text { of poles }\end{array}$ & $\begin{array}{c}\text { Per-unit value } \\
\text { CCW rotation }\end{array}$ & $\begin{array}{c}\text { Per-unit value } \\
\text { CW rotation }\end{array}$ \\
\hline 1 & 8 & 0 & 1.0 \\
\hline 5 & 40 & 0.119 & 0 \\
\hline 7 & 56 & 0 & 0.041 \\
\hline 11 & 88 & 0.018 & 0 \\
\hline 13 & 104 & 0 & 0.021 \\
\hline 35 & 280 & 0.029 & 0 \\
\hline 37 & 296 & 0 & 0.027 \\
\hline
\end{tabular}

The air-gap harmonics were also analyzed by a second method, which was to develop a Fourier series analysis in closed form for the air-gap mmf distribution. The results of this analysis are displayed in Figure 2.

Note that Figure 2 uses a 2 pole fundamental as the base for defining the harmonic fields whereas Tables II, III, and IV use an 8 pole fundamental as the base. The generator was wound as an 8 pole machine so either base is relevant. Therefore, there is a 4:1 difference in the order of harmonics between Figure 1 and Tables II, III, and IV. Also, in Figure 2, the ordinates are field magnitudes and the values reported in Tables II, III, and IV are per-unit.
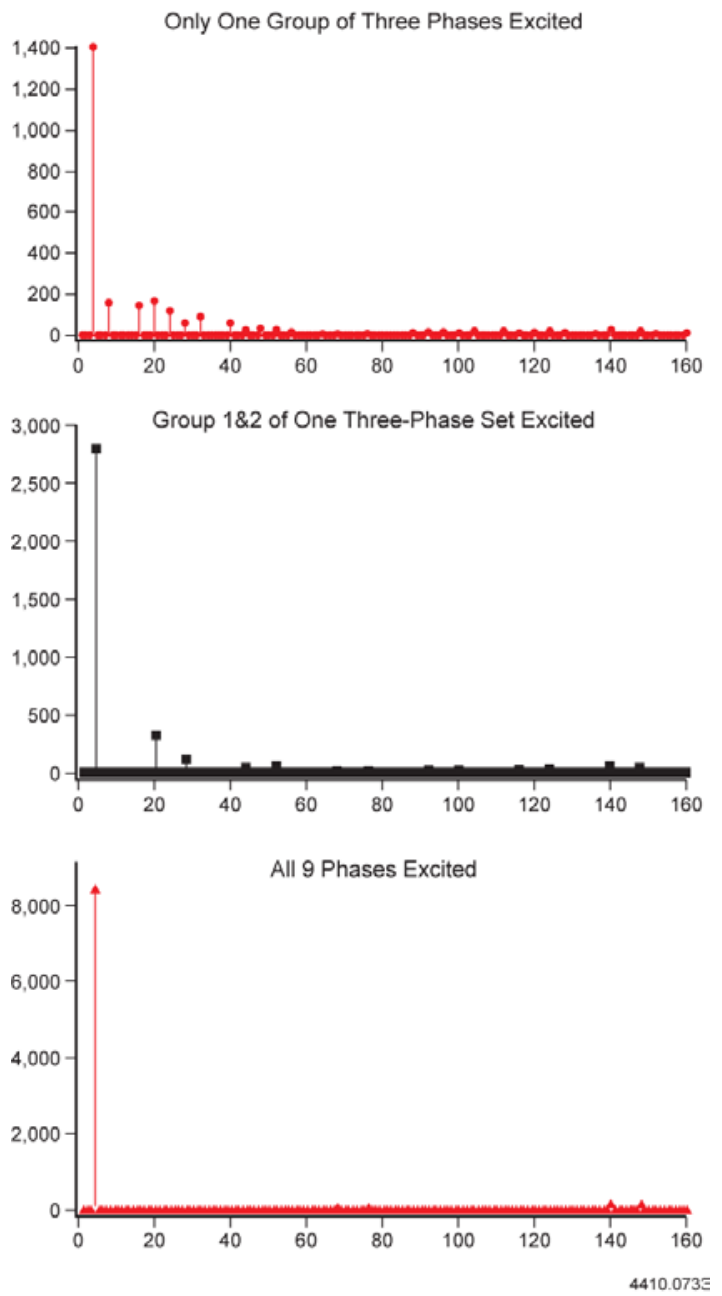

Figure 2. Harmonic content in the MMF wave under different conditions
Mindful of the differences in base values for the calculations, there is excellent agreement between the two different methods that were used for analyzing the air-gap harmonics. The following observations can be made from the results of the harmonic analyses.

\section{DISCUSSION OF HARMONIC ANALYSIS}

The two different methods of analysis provided similar results. Conclusions from the harmonic analyses are as follows:

The nine-phase armature winding mmf contained no harmonics from the fundamental out to the $17^{\text {th }}$ and $19^{\text {th }}$ phasebelt harmonics [10] and the slot harmonics, the $35^{\text {th }}$ and 37 th. The order of the slot harmonics is given by Veinott [7] as

$$
n=r(2 S) \pm 1
$$

where

$$
\begin{aligned}
\mathrm{n} & =\text { order of slot harmonic } \\
\mathrm{S} & =\text { number of stator slots per pole } \\
\mathrm{r} & =\text { any whole number, } 1,2,3
\end{aligned}
$$

The phase-belt harmonics can be minimized by an appropriate selection of coil pitch. However, the slot-harmonics are solely a function of the number of stator slots per pole and cannot be reduced by winding design, i.e. coil pitch.

Most three-phase windings have some harmonics such as the $5^{\text {th }}, 7^{\text {th }}$ etc., in addition to the slot harmonics. In applications in which minimum harmonics are required, a 9-phase winding can be advantageously used because of its very low harmonic content.

The strengths of the harmonic fields for the cases displayed in Tables III and IV are sufficient to cause the speed-torque cusps that result in subsynchronous "crawling" that was observed during the first test. There are several harmonics, particularly in the case of Table III, that exceed the 4 to 5\% harmonics that are typical of balanced three-phase windings.

Figure 3 illustrates the production of cusps in the speedtorque curve of an induction motor that results from the presence of harmonics in the air-gap field.

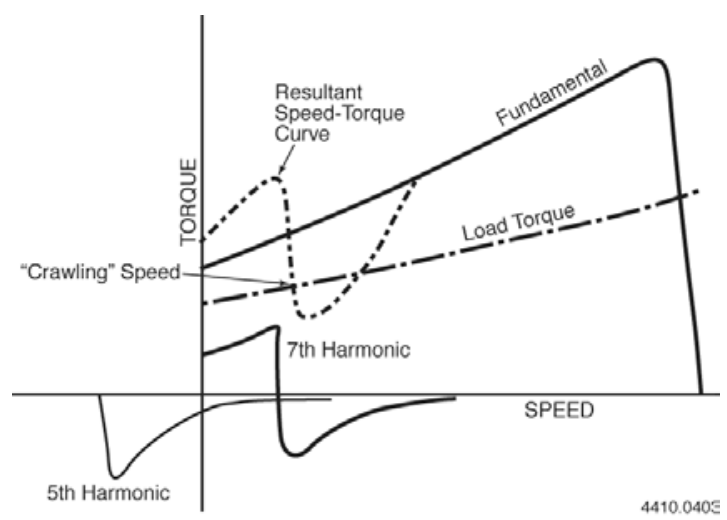

Figure 3. Speed torque curve for an induction motor with the effects of air gap harmonics 
During the first series of tests reported in Table I, the direction of rotation reversed when the excitation was changed between exciting only north poles to exciting both north and south poles simultaneously. This is puzzling and there is no completely clear explanation of this phenomenon that one can obtain by just examining the harmonics reported in Tables III and IV. It is clear from Table III that the north pole only case is rich in harmonics compared to the cases represented by Tables II and IV. The presence of some very strong even harmonics in Table III rotating in the CCW direction plus the strong $5^{\text {th }}$ harmonic also rotating in the CCW direction apparently provided sufficient torque at zero speed to start the motor in the CCW direction.

The harmonic analysis confirmed that the nine-phase winding had an excellent harmonic spectrum.

\section{CONCLUSIONS}

A nine-phase generator armature winding has been presented in which each phase is displaced 40 electrical degrees from the preceding phase in space orientation.

A harmonic analysis of this winding reveals that the space harmonic content is almost zero out to the slot harmonics which, in this machine, are the $35^{\text {th }}$ and $37^{\text {th }}$ harmonics. The nine-phase winding, with an appropriate choice of coil span, is potentially useful in applications where a low harmonic content is of value.

An experimental verification of the windings performance is presented.

Two different methods of analyzing a winding for space harmonics, even though the winding has an irregular pattern of excited conductors, have been presented.

\section{REFERENCES}

[1] E. A. Klingshirn, "High Phase Order Induction Motors, Part IDescription and Theoretical Considerations." IEEE Transactions on Power Apparatus and Systems, Vol. PAS-102, January 1983.

[2] E. A. Klingshirn, "High Phase Order Induction Motors, Part IIExperimental Results.” IEEE Transactions on Power Apparatus and Systems, Vol. PAS-102, January 1983.

[3] R. H. Nelson and P. C. Krause, "Induction Machine Analysis for Arbitrary Displacement Between Multiple Winding Sets.” IEEE Transactions on Power Apparatus and Systems, Vol. PAS-93, May/June 1974.

[4] C. E. Coates, D. Platt, V. J. Gosbell,’Performance Evaluation on NinePhase Synchronous Reluctance Drive." Conference Record, IEEE Industry and Applications Society Annual Meeting, Sept. 30-Oct. 4, 2001.

[5] Steve Williamson and Sandy Smith, "Pulsating Torque and Losses in Multiphase Induction Machines". IEEE Transactions on Industry Applications, Vol. 39, No. 4 July/August 2003.

[6] M. Benatmane, T. McCoy, T. Dalton and T. L. Cooper, "Electric Power Generation and Propulsion Motor Development for US Navy Surface Ships". Presented at the All Electric Ship: Developing Benefits for Maritime Applications Conference, London, U.K., Sept. 1998.

[7] C. G. Veinott, "Theory and Design of Small Inductions Motors", New York, McGraw-Hill Book Company, 1959.

[8] C. G. Veinott, "Spatial Harmonic Magnetomotive Forces in Irregular Windings and Special Connections of Polyphase Windings", IEEE Power Apparatus and Systems, Transactions, 1964.
[9] S. A. Nasar, "Handbook of Electric Machines", New York: Mc-GrawHill, 1987.

[10] P. L. Alger, “The Nature of Polyphase Induction Machines”, New York, John Wiley \& Sons, Inc., 1951

\section{APPENDIX A: HARMONIC MAGNETOMOTIVE FORCES IN A NINE-PHASE WINDING}

The purposes of conducting a harmonic analysis of the nine-phase winding are:

- $\quad$ Determine the harmonic content of the generated nine-phase waveform produced by the generator.

- Explain the subsynchronous "crawling” that was observed when the nine-phase induction motor was excited with three-phase power on only part of the winding.

All of this was discussed in the main body of this paper. This appendix will describe the technique, which was used to conduct the harmonic analysis.

Veinott [8] describes a technique for calculating the harmonics for windings that are not the conventional threephase, lap winding. Veinott's technique, with one exception, which is discussed below, was used here. The technique calculates two quantities, a pitch factor, kpn, and a distribution factor, kdn. The pitch factor calculation is described in many texts such as "Handbook of Electric Machines" [9] and is given as

$$
k p n=\sin \frac{n \beta}{2}
$$

where

$$
\begin{aligned}
& n=\text { order of the harmonic } \\
& \beta=\text { coil span in electrical radians }
\end{aligned}
$$

The distribution factor is the term that accounts for the nine-phase connection as well as the irregular distribution of conductors in the cases where only part of the winding is excited with a three-phase power supply. The equations for performing this calculation are given in [8] and will not be repeated here. However, a qualitative description of the method will be provided. The method depends upon the fact that a coil supplied with a sinusoidal alternating current generates a pulsating magnetomotive force (mmf) wave. This mmf wave can be resolved into two oppositely rotating waves, each of one-half of the magnitude of the original pulsating wave. The calculating algorithm does the bookkeeping of keeping track of the space positions of all of the forward and backward rotating fields for each excited coil and sums them for one particular instant in time. This sum divided by the arithmetic sum of the mmf waves is the distribution factor, kdn, for the nth harmonic. A winding factor, kwn, is calculated for each harmonic.

$$
k w n=k p n \bullet k d n
$$

The per-unit value of each mmf harmonic presented in Tables II, III, and IV is calculated by equation (A-3) 


$$
\text { perunit }=\frac{k w n}{k w 1}
$$

One rather significant modification had to be incorporated into the algorithm described by Veinott in [8].

The equation for the distribution factor of the forward revolving field given in [8] as

$$
k d f n=\frac{\sqrt{\left(\sum \sin \theta f n\right)^{2}+\left(\sum \cos \theta f n\right)^{2}}}{Q}
$$

where

$\mathrm{kdfn}=$ distribution factor for the forward revolving field and the nth harmonic

$\theta f n=$ the space position of the forward revolving field for each coil that is conducting current and for the nth harmonic

$\mathrm{Q}=$ the total number of coils carrying current
There is a similar expression for the backward revolving field. It was found to be necessary to multiply the sin and cos functions by a factor defined as follows.

mmfactor $=1.0$ if the $\mathrm{i}^{\text {th }}$ conductor is connected to a source of excitation.

$=0$ if the $\mathrm{i}^{\text {th }}$ conductor is not connected to a source of excitation.

Otherwise, for some of the three-phase excitation cases that were considered here, the distribution factor calculated a value greater than 1.0, which is impossible based on the definition of distribution factor.

A Mathcad program was developed using the algorithm described in [8] plus the added "mmfactor" described above. The program was first checked against several published examples and then used to calculate the values entered in Tables II, III, and IV in the main section of this paper. 